\title{
Epigenetic inactivation of mir-34b/c in addition to mir-34a and DAPK1 in chronic lymphocytic leukemia
}

\author{
Lu Qian Wang ${ }^{1}$, Yok Lam Kwong ${ }^{1}$, Kit Fai Wong ${ }^{2}$, Chi Shan Bonnie Kho ${ }^{3}$, Dong Yan Jin ${ }^{4}$, Eric Tse ${ }^{1}$,
} Anders Rosèn ${ }^{5}$ and Chor Sang Chim ${ }^{1 *}$

\begin{abstract}
Background: TP53 mutation/deletion is uncommon in chronic lymphocytic leukemia (CLL). We postulated that components of TP53-centered tumor suppressor network, miR-34b/c, in addition to DAPK1 and miR-34a might be inactivated by DNA hypermethylation. Moreover, we tested if miR-34b/c methylation might correlate with miR-203 or miR-124-1 methylation in CLL.

Methods: miR-34b/c, miR-34a and DAPK1 methylation was studied in 11 normal controls, 7 CLL cell lines, and 78 diagnostic CLL samples by methylation-specific polymerase chain reaction. MEC-1 cells were treated with 5-Aza-2'-deoxycytidine for reversal of methylation-associated miRNA silencing. Tumor suppressor properties of miR-34b were demonstrated by over-expression of precursor miR-34b in MEC-1 cells.

Results: miR-34b/c promoter was unmethylated in normal controls, but completely methylated in 4 CLL cell lines. miR-34b/c expression was inversely correlated with miR-34b/c methylation. Different MSP statuses of miR-34b/c, including complete methylation and complete unmethylation, were verified by quantitative bisulfite pyrosequencing. 5-Aza-2'-deoxycytidine treatment resulted in promoter demethylation and miR-34b re-expression in MEC1 cells. Moreover, over-expression of miR-34b resulted in inhibition of cellular proliferation and increased cell death. In primary CLL samples, miR-34a, miR-34b/c and DAPK1 methylation was detected in $2.6 \%, 17.9 \%$ and $34.6 \%$ of patients at diagnosis respectively. Furthermore, 39.7\%, 3.8\% and 2.6\% patients had methylation of one, two or all three genes respectively. Overall, $46.2 \%$ patients had methylation of at least one of these three genes. Besides, miR-34b/c methylation was associated with methylation of miR-34a ( $P=0.03)$ and miR-203 $(P=0.012)$ in CLL.

Conclusions: Taken together, miR-34b/c is a tumor suppressor miRNA frequently methylated, and hence silenced in CLL. Together with DAPK1 methylation, miR-34b/c methylation is implicated in the disruption of the TP53-centered tumor suppressor network. Moreover, the association of miRNA methylation warrants further study.
\end{abstract}

Keywords: MicroRNA, TP53 network, Tumor suppressor, DNA methylation, Chronic lymphocytic leukemia

\section{Background}

DNA methylation refers to the chemical modification of the cytosine ring in a CPG dinucleotide by the addition of a methyl group $\left(-\mathrm{CH}_{3}\right)$ to the 5-carbon position of the cytosine pyrimidine ring in DNA, leading to the formation of 5-methylcytosine (5meC) [1]. Global DNA hypomethylation and aberrant, locus-specific DNA methylation of

\footnotetext{
* Correspondence: jcschim@hku.hk

'Department of Medicine, Queen Mary Hospital, The University of Hong Kong, Hong Kong, China

Full list of author information is available at the end of the article
}

the promoter-associated $\mathrm{CpG}$ islands of tumor suppressor genes (TSGs) are the hallmarks of many human cancers [2-4]. It has been reported that methylation of TSG results in dysregulation of the cell cycle $(C D K N 2 A / B)$, apoptosis (DAPK1/CDKN2A/APAF1), WNT (soluble WNT inhibitors) and JAK/STAT signaling (SOCS1 and PTPN6) in leukemia, lymphoma and myeloma, suggesting that TSG methylation plays an important role in the pathogenesis of various hematological cancers [5-8]. In chronic lymphocytic leukemia (CLL), TSGs including

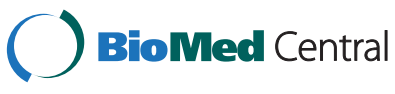

(c) 2014 Wang et al.; licensee BioMed Central Ltd. This is an Open Access article distributed under the terms of the Creative Commons Attribution License (http://creativecommons.org/licenses/by/2.0), which permits unrestricted use, distribution, and reproduction in any medium, provided the original work is properly credited. The Creative Commons Public Domain Dedication waiver (http://creativecommons.org/publicdomain/zero/1.0/) applies to the data made available in this article, unless otherwise stated. 
DAPK1, SFRP1 or SFRP2 have been shown to be aberrantly methylated (hypermethylated) [9-11].

Mature microRNA (miRNAs) are a class of endogenous, single-stranded, non-protein-coding small RNAs measuring 19 to 25 nucleotides (nts), which are responsible for the downregulation of targeted protein $[12,13]$. miRNAs involved in carcinogenesis may be either oncogenic (oncomirs) or tumor suppressive [14]. Recently, tumor suppressive miRNAs have also shown to be silenced by aberrant DNA methylation in cancers [1].

Recently, DNA methylation of $m i R-34 b / c$ has been demonstrated in colorectal cancer, lung cancer and acute lymphoid leukemia. $m i R-34 b / c$, like $m i R-34 a$, is under the transcriptional regulation of TP53. TP53 inactivation, mostly via mutations, occurs in up to $50 \%$ epithelial cancers at diagnosis $[15,16]$. In contrast, TP53 mutation or del (17p) is only found in only $5 \%$ to $10 \%$ of CLL patients at diagnosis [17-19]. Therefore, other mechanisms leading to TP53 malfunction may exist. In this connection, methylation of DAPK1 gene, which triggers TP53 activation upon oncogenic cellular transformation, was first reported as a TSG methylated in CLL [20], and subsequently shown to contribute to CLL progression by blocking the apoptosis of leukemia cells [10]. Moreover, since the miR-34 family is a transcriptional target of TP53, its methylation might lead to the perturbation of the TP53 tumor suppression pathway. In this report, we performed a comprehensive methylation study of the TP53-centered tumor suppressor network by studying DNA methylation of $m i R-34 a$ and DAPK1 in addition to $m i R-34 b / c$ in a representative cohort of CLL.

\section{Materials and methods Patient samples}

This study has been approved by the Institutional Review Board of Queen Mary Hospital and written informed consent has been obtained in accordance with the Declaration of Helsinki. Diagnostic bone marrow samples were obtained in $78 \mathrm{CLL}$ patients. Diagnosis of CLL was made according to the WHO Classification, which is based on classical morphology, low level of expression of light-chain-restricted surface immunoglobulin, and dual positivity of CD5 and CD23 in the neoplastic lymphocytes as demonstrated by flow cytometry $[21,22]$. There were $51(65.4 \%)$ male and 27 female (34.6\%) patients with a median age of 65 years (range: 37-91 years). The median presenting lymphocyte count was $18 \times 10^{9} / 1$ (range: $10-540 \times 10^{9} / \mathrm{l}$ ). Among 70 patients with information for Rai staging, there were $42(60.0 \%)$ patients with limited Rai stage (< stage II) and 28 (40.0\%) with advanced Rai stage ( $\geq$ stage II) disease. Of the 48 patients with cytogenetic data, $12(25.0 \%)$ carried high/intermediate-risk cytogenetic aberrations [del (17p), $\mathrm{N}=2$; del (11q), $\mathrm{N}=1$; trisomy $12, \mathrm{~N}=9$ ] and $36(75.0 \%)$ carried low/standard- risk cytogenetic alterations [del (13q), $\mathrm{N}=11$; normal karyotype, $\mathrm{N}=18$; other karyotypic changes, $\mathrm{N}=7$ ]. The median overall survival (OS) of the cohort was 69 months. The median OS of those with Rai stage $>2$ and those Rai stage $\leq 2$ were 49 and 111 months respectively $(P=0.006)$. Moreover, the median OS for those with or without high/intermediate-risk karyotype were 28 months and 111 months $(\mathrm{P}=0.003)$. Of these, the miR-34a and $D A P K 1$ methylation results of 50 patients have previously been reported [20,23]. Therefore, in this study, $D A P K 1$ and miR-34a methylation were studied in an additional 28 diagnostic CLL primary samples.

\section{Cell lines and culture}

The CLL cell lines MEC1 and CLL-AAT were purchased from Deutsche Sammlung von Mikroorganismen und Zellkulturen Deutsche GmbH (DMSZ) (Braunschweig, Germany) and American Type Culture Collection (Manassas, USA) respectively. MEC2, WAC3CD5+ and I83-E95 were kindly provided by Dr John C. Byrd, Department of Medicine, Ohio State University [24,25]. Moreover, HG3 and 232B4 were kind gifts from Prof. Anders Rosén, Department of Clinical \& Experimental Medicine, Linköping University [25,26]. Cell lines were maintained in 90\% RPMI $1640+10 \%$ FBS. Culture media were supplemented with $50 \mathrm{U} / \mathrm{ml}$ penicillin and $50 \mu \mathrm{g} / \mathrm{ml}$ streptomycin (Invitrogen, Carlsbad, CA, USA), and maintained in a humidified atmosphere of $5 \% \mathrm{CO}_{2}$ at $37^{\circ} \mathrm{C}$.

\section{Methylation-specific polymerase chain reaction (MSP)}

DNA was extracted from bone marrow samples of CLL at diagnosis, the cell lines and 11 normal controls (peripheral blood buffy coats obtained from 5 healthy donors, bone marrow buffy coat from 3 healthy donors, and CD19 sorted peripheral blood B-cells from 3 healthy controls) by standard method. The normal controls comprised 5 males and 6 females with a median age of 38 years (range: 25-60 years). Treatment of DNA with bisulfite for conversion of unmethylated cytosine to uracil (but unaffecting methylated cytosine) was performed with a commercially available kit (EpiTect Bisulfite Kit, QIAGEN, Hilden, Germany). Details of primers and conditions for MSP of $m i R-34 b / c, m i R-34 a$ and DAPK1 were given in Table 1 . To define the sensitivity of $m i R-34 a$ M-MSP, $1 \mu \mathrm{g}$ of methylated control DNA was 10 -foldedly serially diluted in buffer, bisulfite-treated and amplified with miR-34a M-MSP primers.

\section{Quantitative bisulfite pyrosequencing}

DNA was treated with bisulfite and used as template. Primers for pyrosequencing were used to amplify the promoter region, which was overlapped with the amplicon of MSP. Primers were designed using PSQ Assay Design software (Biostage). Forward primer: 5’- 
Table 1 miR-34a, miR-34b/c and DAPK1 MSP Primer sequences and the reaction condition

\begin{tabular}{|c|c|c|c|c|}
\hline Gene & Forward primer ( $5^{\prime}$ to $\left.3^{\prime}\right)$ & Reverse primer ( $5^{\prime}$ to $\left.3^{\prime}\right)$ & $\mathrm{Tm} /$ cycles $/ \mathrm{MgCl}_{2}$ & References \\
\hline \multicolumn{5}{|c|}{$m i R-34 a$} \\
\hline U-MSP & GGGGATGAGGATTAGGATTT & CAAACAAAACACATAAAAACAACA & $58^{\circ} \mathrm{C} / 35 \times / 1.5 \mathrm{mM}$ & [23] \\
\hline M-MSP & GGGGATGAGGATTAGGATTTC & ACAAAACGCATAAAAACGACG & $58^{\circ} \mathrm{C} / 35 \times / 1.5 \mathrm{mM}$ & \\
\hline \multicolumn{5}{|c|}{$m i R-34 b / c$} \\
\hline U-MSP & TITTATTTGTTTGTTTGTGTTGTTTGG & CAACTACAACTCCCAAACAATCC & $56.5^{\circ} \mathrm{C} / 38 \times / 2 \mathrm{mM}$ & {$[27,28]$} \\
\hline M-MSP & ATTCGTTTCGTTTCGCGTTCGTTC & CGACTACAACTCCCGAACGATCCG & $60^{\circ} \mathrm{C} / 34 \times / 2 \mathrm{mM}$ & \\
\hline \multicolumn{5}{|l|}{ DAPK1 } \\
\hline U-MSP & GGAGGATAGTTGGATTGAGTTAATGTT & CAAATCCСТCCCAAACACCAA & $63^{\circ} \mathrm{C} / 35 \times / 1.5 \mathrm{mM}$ & [20] \\
\hline M-MSP & GGATAGTCGGATCGAGTTAACGTC & CCCTCCCAAACGCCGA & $63^{\circ} \mathrm{C} / 35 \times / 1.5 \mathrm{mM}$ & \\
\hline
\end{tabular}

Abbreviations: M-MSP MSP for the methylated allele, U-MSP MSP for the unmethylated allele, Tm annealing temperature.

GGAAGGGGAGGTTTGGTA-3'; Reverse primer: 5'-ACC ACCACAATACAATCAACTAATA-3'; condition: $2 \mathrm{mM} /$ $59^{\circ} \mathrm{C} / 50 \mathrm{X}$. A stretch of DNA with 12 adjacent CpG dinucleotides was pyrosequenced by sequencing primer: 5'-CAACTAATAACACTACCTACA-3'.

\section{5-Aza-2'-deoxycytidine (5-AzadC) treatment}

MEC1 cells were cultured in six-well plates at $1 \times 10^{6}$ cells/ml, with $0.5 \mu \mathrm{M}$ of 5 -AzadC (Sigma-Aldrich, St. Louis, MO, USA) for 5 days. Cells on day 0 and day 5 of 5-AzadC treatment were harvested.

\section{Quantification of miR-34b and reverse transcription-PCR of DAPK1}

According to the respective manufacturer's instructions, total RNA was isolated and reversely transcribed using the mirVana miRNA Isolation Kit. miRNA was quantified by the TaqMan MicroRNA RT Kit, and TaqMan MicroRNA Assay Kit as reported [27-29]. RNU48 was chosen as reference for data analysis using the $2^{-\Delta \Delta} \mathrm{Ct}$ method [30]. Moreover, for semi-quantitative analysis of DAPK1 expression, $D A P K 1$ was reversely transcribed by the QuantiTect Reverse Transcription Kit (QIAGEN, Valencia, CA) [31]. Reverse transcription-PCR primers and PCR condition for $D A P K 1$ were summarized in Table 2.

\section{Western blot for DAPK1}

MEC1, MEC2, 232B4, CLL-AAT and WAC3CD5+ cells were harvested and then lysed in RIPA buffer $(50 \mathrm{mM}$ Tris- $\mathrm{HCl}, \mathrm{pH} 7.4,150 \mathrm{mM} \mathrm{NaCl}, 0.2 \%$ SDS, 1\% Triton
X-100, 2 mM EDTA). Protein lysates were resolved on $6 \%$ SDS-PAGE and electrotransferred onto a $0.2 \mu \mathrm{m}$ nitrocellulose membrane (Bio-Rad, Hercules, CA). The membranes were blocked and incubated with antiDAPK1 (1:1000; Sigma-Aldrich, USA) or anti-actin (1:5000; Sigma-Aldrich, USA) primary antibody at $4^{\circ} \mathrm{C}$ overnight. Then membranes were washed three times and incubated with anti-rabbit horseradish peroxidase conjugate secondary antibody at room temperature for 1 hour. Protein signals were detected by ECL Prime Western blotting detection reagents (Amersham Biosciences, Buckinghamshire, UK).

\section{Precursor miR-34b overexpression}

Precursor miR-34b (100nM; Ambion) (oligonucleotide mimic) was transfected into $1 \times 10^{6} \mathrm{MEC} 1$ cells using X-tremeGENE siRNA Transfection Reagent (Roche Diagnostics/Roche, Basel, Switzerland), according to the manufacturers' instructions [28]. Non-targeting oligonucleotide mimic was used as negative control.

\section{Proliferation, viability and cell cycle analyses}

To document the tumor suppressor function of miR$34 b$, three independent transfections were performed, in which functional studies including MTT assay, Trypan blue exclusion assay and the percentage of sub-G1 fraction were performed in triplicate after each transfection. The MTT method was used to determine cellular proliferation. Cells were cultured in a 96-well microtitre plate at $2.5 \times 10^{4} /$ well in $100 \mu \mathrm{l}$ of medium. At test time-

Table 2 Primer sequences and the reaction condition of DAPK1 and GAPDH Reverse transcription-polymerase chain reaction (RT-PCR)

\begin{tabular}{|c|c|c|c|c|}
\hline Gene & Forward primer $\left(5^{\prime}\right.$ to $\left.3^{\prime}\right)$ & Reverse primer $\left(5^{\prime}\right.$ to $\left.3^{\prime}\right)$ & $\mathrm{Tm} / \mathrm{cycles} / \mathrm{MgCl}_{2}$ & References \\
\hline DAPK1 & CAGTTTGCGGTTGTGAAGAA & CCTGCAACGAGTTCCAAGAT & $53^{\circ} \mathrm{C} / 35 \times / 2 \mathrm{mM}$ & {$[31]$} \\
\hline GAPDH & ACCACAGTCCATGCCATCACT & TCCACCACCCTGTTGCTGTA & $60^{\circ} \mathrm{C} / 24 \times / 2 \mathrm{mM}$ & {$[23]$} \\
\hline
\end{tabular}


points, $10 \mu \mathrm{l}$ of $5 \mathrm{mg} / \mathrm{ml} \mathrm{MTT} \mathrm{reagent} \mathrm{was} \mathrm{added} \mathrm{to} \mathrm{each}$ well and incubated for 4 hours, after which $100 \mu \mathrm{l}$ of dimethyl sulfoxide (DMSO) was added, and absorbance at $550 \mathrm{~nm}$ with reference to $650 \mathrm{~nm}$ was measured. Cellularity viability assay was performed by the Trypan blue dye exclusion assay. For cell cycle analysis, test cells were washed in phosphate buffered saline (PBS), fixed in cold 70\% ethanol at $4^{\circ} \mathrm{C}$ overnight, washed twice in PBS, resuspended and incubated in $50 \mu \mathrm{g} / \mathrm{ml}$ PI staining solution with $5 \mu \mathrm{g} / \mathrm{ml}$ RNase $\mathrm{A}$ at $4^{\circ} \mathrm{C}$ for at least 2 hours, and then analyzed by flow cytometry (Beckman Coulter Cytomics FC 500).

\section{Statistical analysis}

In CLL, correlation between DAPK1, miR-34a and $m i R$ $34 \mathrm{~b} / \mathrm{c}$ methylation status with continuous (mean age, mean diagnostic haemoglobin $(\mathrm{Hb})$, lymphocyte or platelet counts at diagnosis) and categorical variables (gender, Rai stage or high-risk karyotypes) were studied respectively by Student's t-test and chi-square test (or Fisher's exact test). Moreover, in 50 samples, the methylation of $m i R-203$, $m i R-124-1$ has been studied [29,32], and the association of $m i R-34 b / c$ with the methylation of $m i R-203$ and $m i R-124$ 1 was analyzed by chi-square test. OS is measured from the date of diagnosis to the date of last follow-up or death. OS of patients with limited Rai stage (stages 0, I and II) was compared to those with advanced Rai stage (stages III and IV). Moreover, OS of patients with high-risk karyotypes [del (17p), del (11q) or trisomy 12] was compared with those with standard-risk karyotypes [del (13q), normal karyotype or other karyotypic changes]. The mean values of MTT assay, Trypan blue exclusion assay and sub-G1 fraction in MEC1 cells transfected with precursor $m i R-34 b$ mimic were compared with negative control transfected with a scrambled oligo by Student's t-test. Survival is plotted by the Kaplan-Meier method and compared by the log-rank test. All P values were two-sided.

\section{Results}

MSP

\section{Controls}

None of the 8 normal peripheral blood controls (N1 to $\mathrm{N} 8$ ) and 3 normal bone marrow controls (N9 to N11) showed aberrant methylation of $m i R-34 b / c, m i R-34 a$ or $D A P K 1$ (Figure 1A). Expected MSP results (normal DNA: U-MSP positive/M-MSP negative; methylated DNA: UMSP negative/M-MSP positive) were demonstrated in the positive and negative controls. Moreover, the sensitivity of miR-34a M-MSP was $10^{-2}$ (Figure $1 \mathrm{~B}$ ).

\section{CLL cell lines}

The profile of $m i R-34 b / c$ methylation of $7 \mathrm{CLL}$ cell lines was shown in Figure 2A. MEC1, 232B4, I83-E95

\section{A Methylation-specific PCR: Donors}

\section{U-MSP: $m i R-34 b / c$}

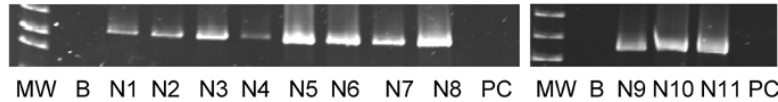

\section{U-MSP: $m i R-34 a$}

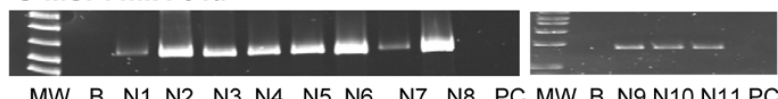

$\begin{array}{llllllllllllllllll}M W & B & \text { N1 } & \text { N2 } & \text { N3 } & \text { N4 } & \text { N5 } & \text { N6 } & \text { N7 } & \text { N8 } & \text { PC } & \text { MW } & B & \text { N9 N10 N11 PC }\end{array}$

\section{U-MSP: DAPK1}

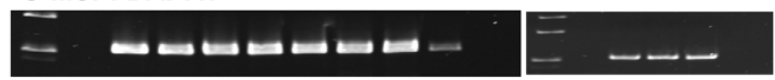

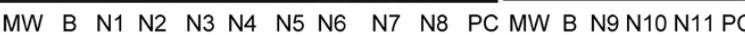

\section{M-MSP: $m i R-34 b / c$}

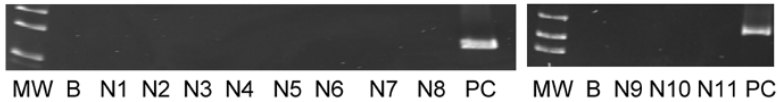

M-MSP: $\operatorname{miR}-34 a$
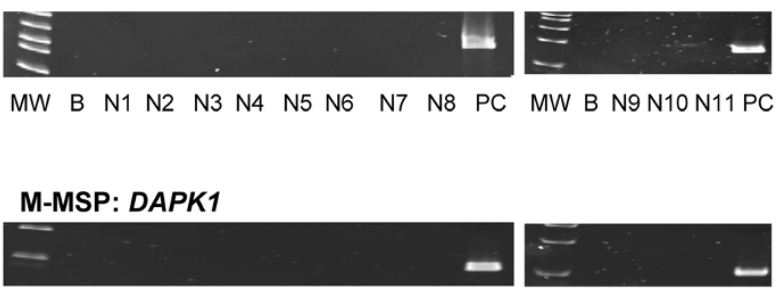

$\begin{array}{lllllllllllll}M W & B & \text { N1 } & \text { N2 } & \text { N3 } & \text { N4 } & \text { N5 } & \text { N6 } & \text { N7 } & \text { N8 } & \text { PC } & \text { MW } & B \\ \text { N9 N10 N11 PC }\end{array}$

\section{B Sensitivity of methylated-MSP of miR-34a}

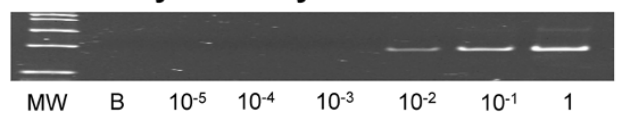

Figure 1 MSP of $m i R-34 b / c, m i R-34 a$ and DAPK1 in controls. (A) U- and M-MSP of miR-34b/c, miR-34a and DAPK1 showed that the positive control (PC) was completely methylated while all normal controls were completely unmethylated. MW: Marker; B: Reagent blank; N1 to N5: Peripheral blood buffy coat of healthy donors; N6 to N8: CD19 sorted B cells of the peripheral blood from healthy donors; N9 to N11: Bone marrow control of healthy donors; PC: Positive control with methylated DNA. (B) Sensitivity of methylated-MSP of miR-34a. To define the sensitivity of miR-34a M-MSP, $1 \mathrm{\mu g}$ of methylated control DNA was 10-fold serially diluted in buffer, bisulfite-treated and amplified with miR-34a M-MSP primers. MW: marker; B: reagent blank: Serial dilution of methylated positive control from 1 to $10^{-5}$. 


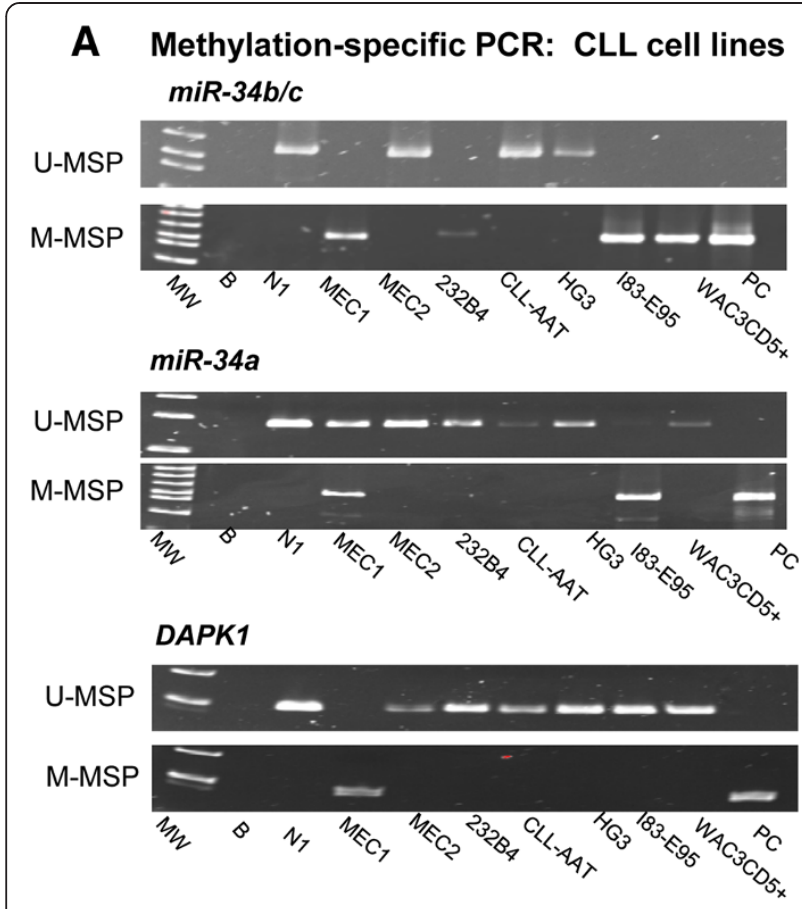

B

\section{miR-34b methylation status}

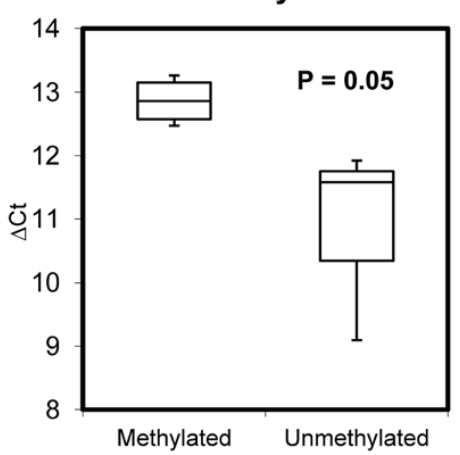

\section{Semi-quantitative RT-PCR analysis of DAPK1 expression in CLL cell lines}

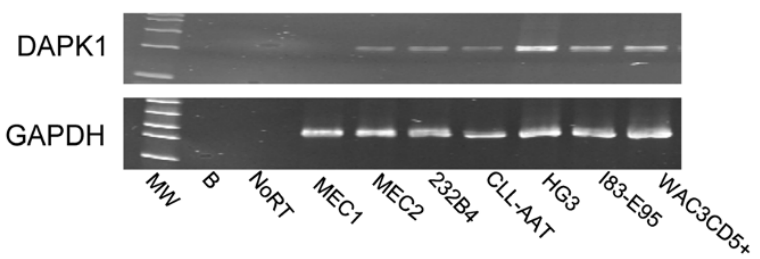

D Sequencing analysis of the semi-quantitative RT-PCR products for the detection of DAPK1 G GA G GACTA A G T C CA G C G G C G G G T G T GA G C C G GA G GACATCGAG C G
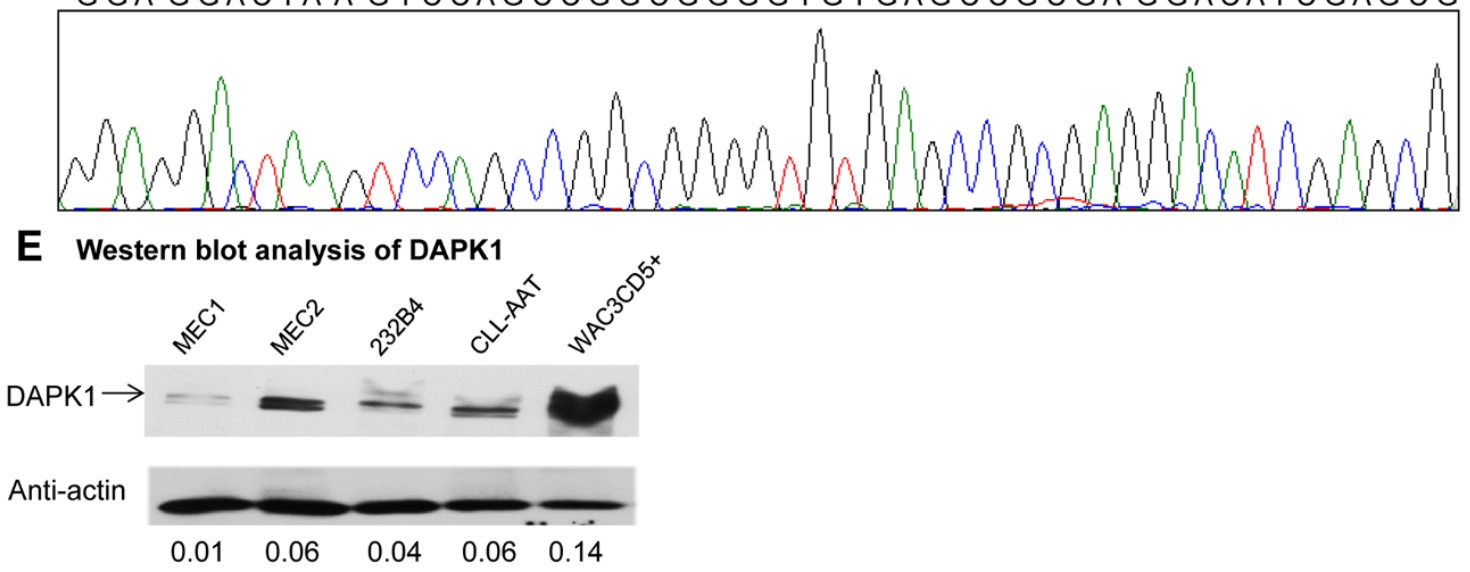

Figure 2 Methylation of $m i R-34 b / c$, miR-34a and DAPK1 in CLL cell lines. (A) In CLL cell lines, MEC1, 232B4, I83-E95 and WAC3CD5+ were completely methylated and MEC2, HG3 and CLL-AAT were completely unmethylated for miR-34b/c. 183-E95 was completely methylated, MEC1 was partially methylated, but MEC2, 232B4, CLL-AAT, HG3 and WAC3CD5+ were unmethylated for miR-34a. Moreover, MEC1 was completely methylated, and other six cell lines were unmethylated for DAPK1. (B) Stem-loop qRT-PCR analysis of the mature miR-34b expression in 7 CLL cell lines. $\triangle \mathrm{Ct}$, Ct miR-34b-Ct RNU48. (C) In CLL cell lines, MEC1 cells showed no DAPK1 mRNA expression while other six cell lines had detectable DAPK1 mRNA levels. (D) Sequencing analysis of the semi-quantitative RT-PCR products for the detection of DAPK1. MW: Marker; B: Reagent blank; N1: Normal donors; NoRT: Negative control without reverse transcriptase; PC: positive control with methylated DNA. (E) Western blot analysis of DAPK1 in MEC1, MEC2, 232B4, CLL-AAT and WAC3CD5+ cells. WAC3CD5+ cells were used as positive control. Anti-actin protein was regarded as the endogenous normalizer and the relative DAPK1 protein level was shown in the bottom row.

and WAC3CD5+ showed complete methylation of miR$34 \mathrm{~b} / \mathrm{c}$ whereas MEC2, HG3 and CLL-AAT were completely unmethylated. Quantitative bisulfite pyrosequencing confirmed the methylation statuses (MM and UU) of CLL cell lines detected by MSP (Additional file 1: Table S1 and Figure S1A-C). On the other hand, $m i R-34 a$ was completely methylated in I83-E95, partially methylated in MEC1 and completely unmethylated in MEC2, 232B4, CLL-AAT, HG3 and WAC3CD5+ (Figure 2A). DAPK1 was completely methylated in MEC1 but completely unmethylated in other six CLL cell lines (Figure 2A).

Moreover, in order to confirm the association of $m i R$ $34 b / c$ expression and methylation in CLL cell lines, the mean $m i R-34 b$ expression and $m i R-34 b / c$ methylation 
level were compared among the 7 CLL cell lines. The results showed the mean miR-34b expression in completely methylated CLL cell lines (MEC1, 232B4, I83-E95 and WAC3CD5+) was significantly lower than that of unmethylated MEC2, HG3 and CLL-AAT, and hence a higher $(\Delta \mathrm{Ct})$ $(\mathrm{P}=0.05)$ (Figure 2B). Furthermore, in CLL cell lines, complete methylation of DAPK1 in MEC1 cells showed absence of $D A P K 1 \mathrm{mRNA}$ expression while other six cell lines without DAPK1 methylation showed detectable DAPK1 mRNA levels (Figure $2 \mathrm{C}$ ). The sequence analysis of semiquantitative RT-PCR of DAPK1 was shown in Figure 2D. Western blot analysis also revealed marked downregulation of DAPK1 protein expression in MEC1 when compared with cells with absence of DAPK1 methylation including MEC2, 232B4, CLL-AAT, WAC3CD5+ cells (Figure 2E).

\section{Primary samples at diagnosis}

(I) miR-34 family

$m i R-34 b / c$ methylation was found in 14 of 78 (17.9\%) patient samples at diagnosis (Figure $3 \mathrm{~A}$ ). No correlation was demonstrated between $m i R-34 b / c$ methylation and the diagnostic $\mathrm{Hb}$ level $(\mathrm{P}=0.76)$, lymphocyte count $(\mathrm{P}=0.51)$ or platelet count $(\mathrm{P}=0.65)$. There was no significant association of $m i R-34 b / c$ methylation with age $(\mathrm{P}=0.97)$, gender $(P=0.76)$, advanced Rai stage $(\geq$ stage 2$)(P=0.75)$ and high-risk karyotypic aberrations $(\mathrm{P}=0.66)$. The median OS of CLL patients with and without $m i R-34 b / c$ methylation were 51 and 69 months respectively $(\mathrm{P}=0.77)$. In addition, miR-34a methylation was present only in $2(2.6 \%)$ of CLL samples (Figure 3B).

Moreover, methylation status of $m i R-203, m i R-34 a$ and miR-124- 1 was available in 50 patients. $m i R-34 b / c$ methylation was found to be associated with the methylation of miR-203 ( $\mathrm{P}=0.012)$ and miR-34a $(\mathrm{P}=0.03)$, but not miR-124-1 $(\mathrm{P}=0.06)$.

\section{(II) DAPK1}

$D A P K 1$ was found in 27 of 78 (34.6\%) patients at diagnosis (Figure $3 \mathrm{C}$ ). Apart from the association with advanced age $(\mathrm{P}=0.04)$, the methylation status of DAPK1 was not associated with other clinical demographics including gender $(\mathrm{P}=0.46)$ and advanced Rai stage $(\geq$ stage 2) $(\mathrm{P}=0.30)$, high-risk karyotypic aberrations $(\mathrm{P}=0.73)$, diagnostic $\mathrm{Hb}$ level $(\mathrm{P}=0.67)$, lymphocyte count $(\mathrm{P}=0.51)$ or platelet count $(\mathrm{P}=0.59)$. The median $\mathrm{OS}$ for CLL

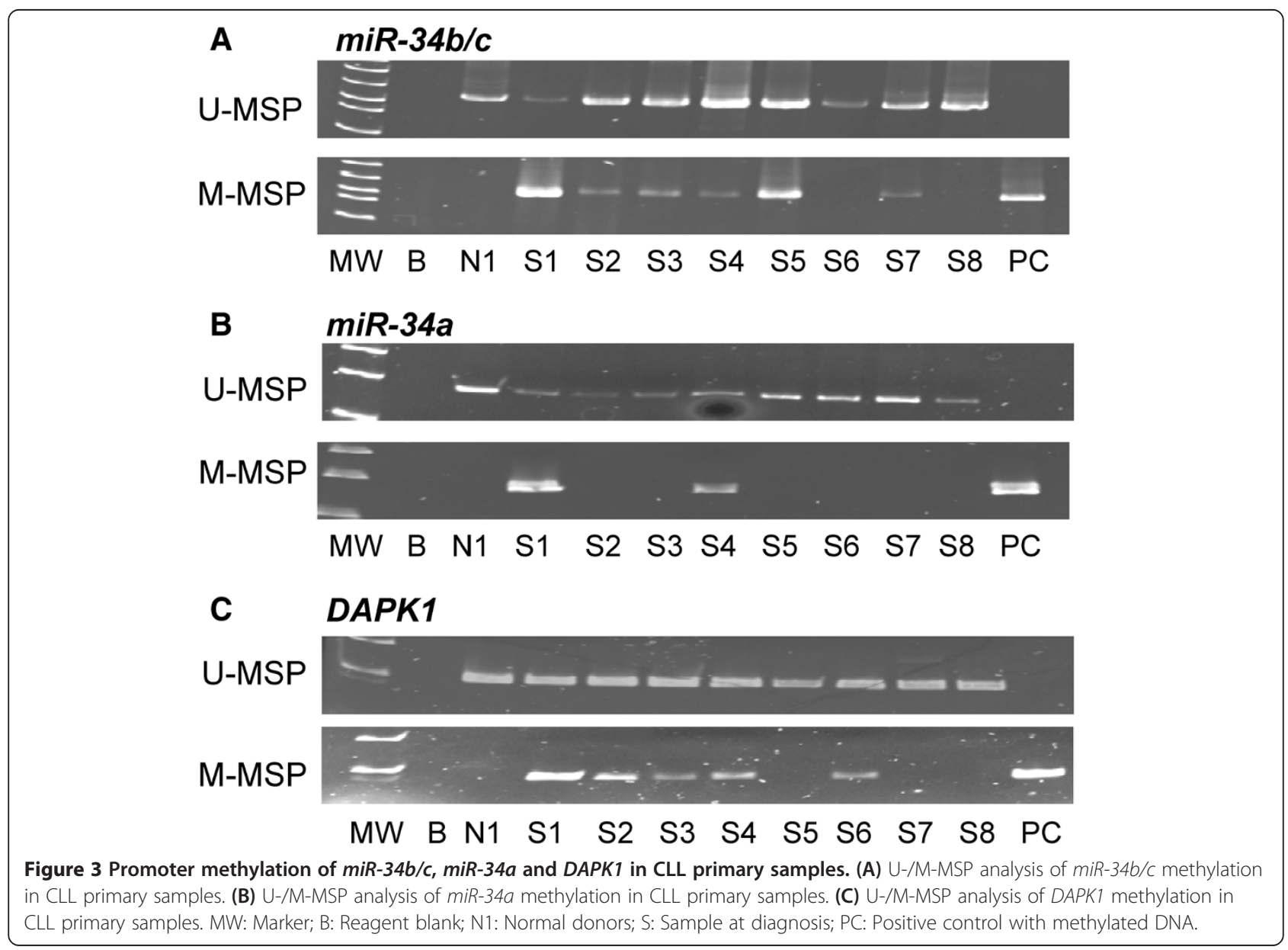


patients with and without DAPK1 methylation were 89 and 68.88 months respectively $(\mathrm{P}=0.98)$. The methylation status of DAPK1 was not associated with that of $m i R-34 b / c$ $(\mathrm{P}=0.99), \operatorname{miR}-34 a(\mathrm{P}=0.12), \operatorname{miR}-124 a(\mathrm{P}=0.40)$ or $m i R-$ 203 ( $\mathrm{P}=0.13)$.

Moreover, we performed MSP of $m i R-34 b / c, m i R-34 a$ and $D A P K 1$ in both peripheral blood and bone marrow samples of patients, in whom both peripheral blood and bone marrow were available. Concordant MSP results of $m i R-34 b / c, m i R-34 a$ and DAPK1 between bone marrow cells and peripheral blood cells were demonstrated, and hence both peripheral blood and marrow tumor cells are valid for methylation study (Figure 4A-C).

Methylation profiling of $m i R-34 a, m i R-34 b / c$ or DAPK1 in primary samples

Among the 78 patients, apart from 53.8\% (42/78) of patients who did not show methylation of any of these three genes, $39.7 \%(31 / 78), 3.8 \%(3 / 78)$ and $2.6 \%(2 / 78)$ of patients had methylation of one, two or all of the three genes respectively. Overall, 46.2\% (36/78) had methylation of at least one of these three genes.

\section{5-AzadC treatment of MEC1 cells}

MEC1 cells were completely methylated for $m i R-34 b / c$. 5-AzadC demethylation treatment of MEC1 cells led to the demethylation of $m i R-34 b / c$ and the emergence of U-MSP signal on day 5 (Figure 5A and Additional file 1: Figure S1D), with the re-expression of mature $m i R-34 b$ shown by TaqMan stem-loop quantitative RT-PCR (Figure 5B).

\section{Effect of miR-34b overexpression in MEC1 cells}

miR-34b was completely methylated for the MEC1 cells, and hence under-expressed. Upon transfection of precursor miR-34b mimic into MEC1 cells, overexpression of mature $m i R-34 b$ was demonstrated by TaqMan stemloop quantitative RT-PCR (Figure 6A). When compared with negative control transfected with a scrambled oligo,

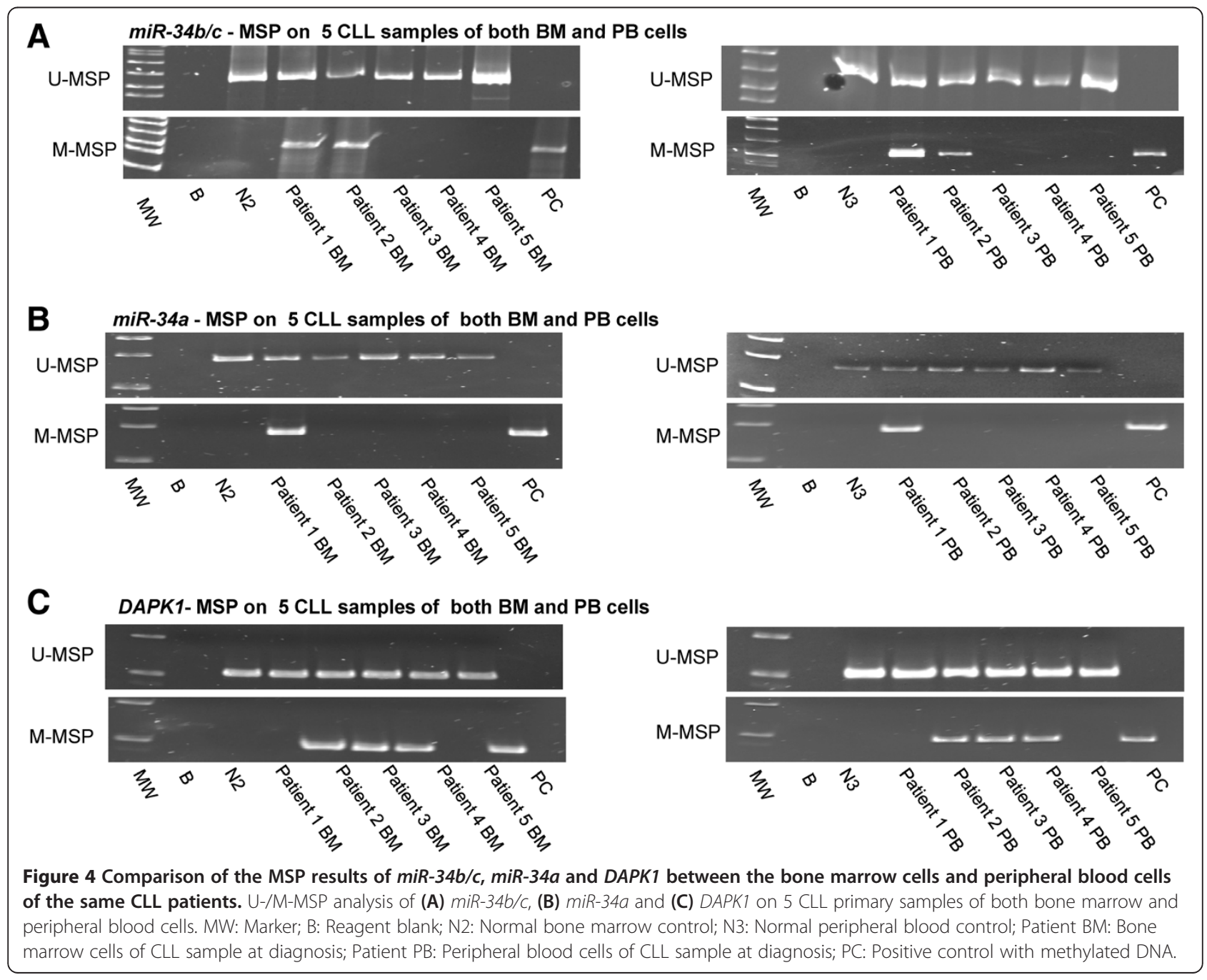



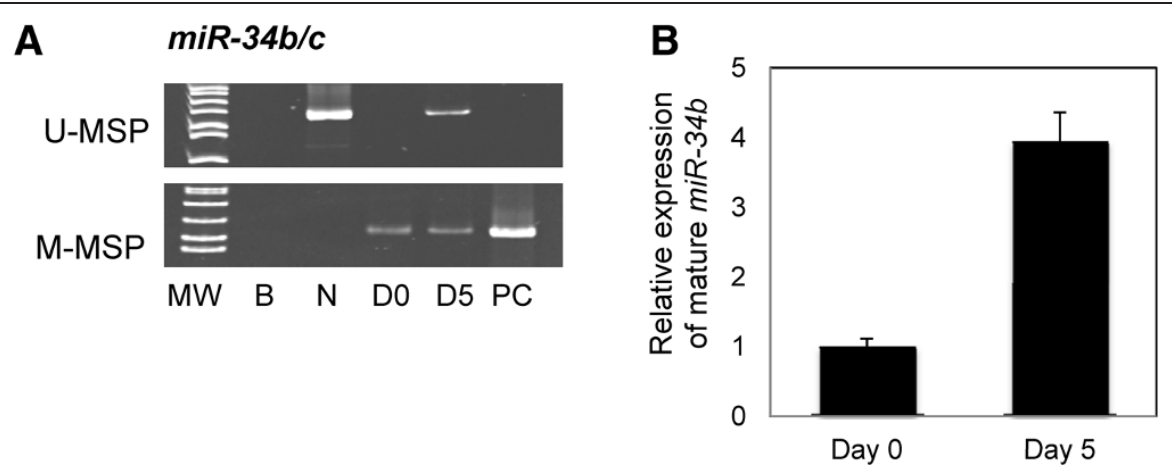

Figure 5 Effect of 5-Aza-2'-deoxycytidine (5-AzadC) treatment on MEC1 cells. (A) U- /M-MSP analysis of miR-34b/c promoter methylation status. (B) stem-loop RT-qPCR analysis of the mature miR-34b expression. 5-AzadC treatment led to the progressive demethylation of miR-34b/C promoter, and re-expression of the mature miR-34b in MEC1 cells. MW: Marker; B: Reagent blank; N: Normal donors; PC: Positive control with methylated DNA; D0: Day 0; D5: Day 5 culture in $0.5 \mu \mathrm{m}$ 5-AzadC.

cells over-expressing miR-34b mimic showed a $13 \%$ reduction of cellular proliferation by MTT assay $(\mathrm{P}=0.03$, Figure $6 \mathrm{~B})$, a $10 \%$ increase of dead cells measured by Trypan blue exclusion assay $(P=0.02$, Figure $6 C)$, in addition to a $12 \%$ increase of cells in sub-G1 phase using propidium iodide staining $(\mathrm{P}=0.02$, Figure $6 \mathrm{D})$, suggesting that $m i R-34 b$ played a tumor suppressive role in CLL cells.

\section{Discussion}

Despite the retrospective nature, our cohort was representative of CLL in view of the prolonged survival, and the expected adverse impact of advanced Rai stage and high-risk karyotype. It is ideal to perform pyrosequencing of primary samples. Unfortunately, only buffy coat has been collected from the primary marrow samples without cell selection. Given that the sensitivity of M-MSP of
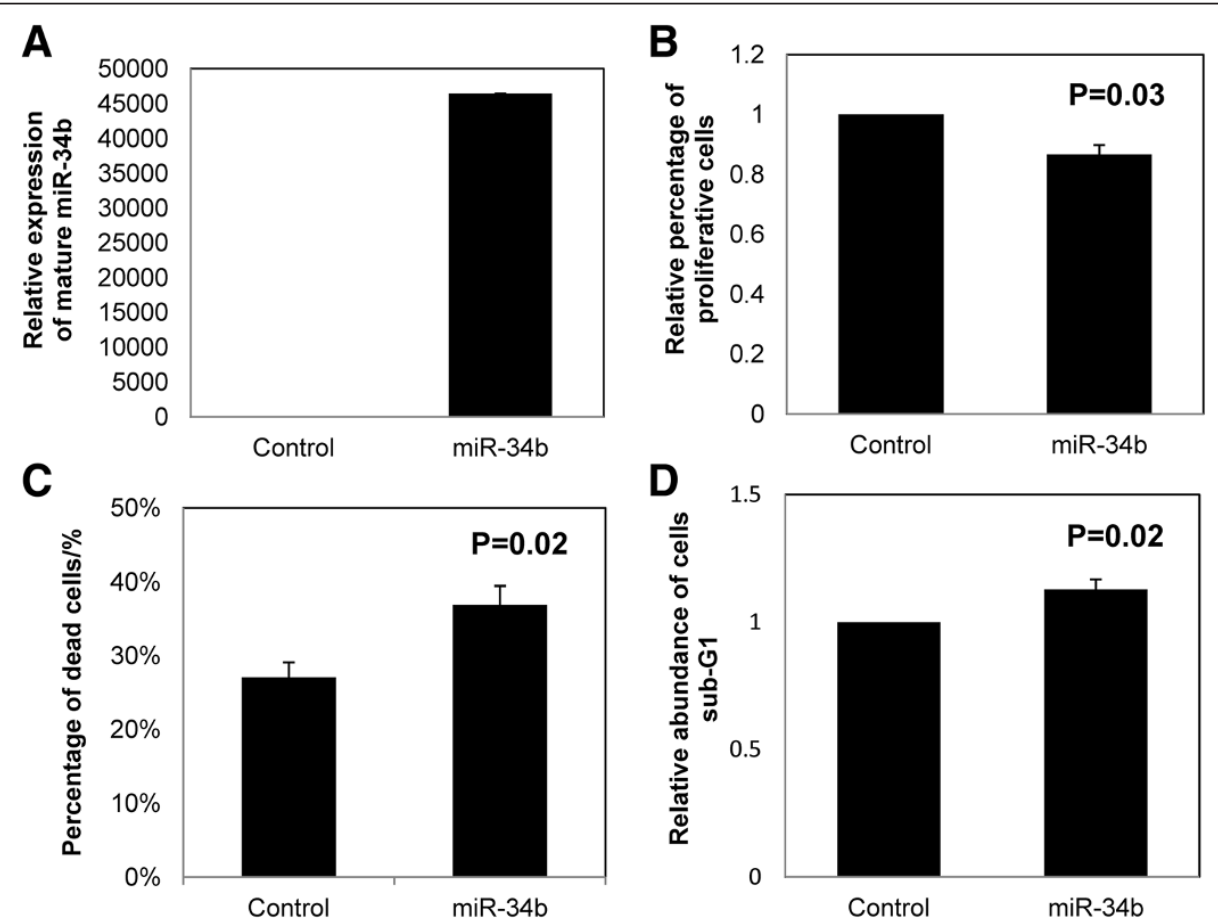

Figure 6 Over-expression of miR-34b in CLL cells. MEC1 cells, completely methylated for miR-34b, were transfected with mature miR-34b mimic or scrambled control oligos. (A) Stem-loop RT-qPCR analysis of mature miR-34b expression at 48 hrs after transfection. (B) Cell proliferation of CLL cells in response to overexpression of miR-34b was measured by MTT assay. (C) Cellular death was measured by Trypan blue exclusion assay. (D) The percentage of apoptotic cells (sub-G1 cells) was measured by the Propidium iodide staining. Values represented the average of the means from each of the 3 experiments performed in triplicate \pm standard deviation. 
miR-34b/c and DAPK1 is $10^{-3}[7,28]$, and that the leukemia infiltration ranged from $36 \%$ to $95 \%$ (median: 64\%), our results are still valid even without CD19 cell sorting of primary samples. Moreover, in patients in whom both peripheral blood and bone marrow buffy coats were available, concordant MSP results for $m i R-34 b / c, m i R-34 a$ and DAPK1 were demonstrated, and hence both peripheral blood and bone marrow were valid for methylation analysis. Based on these experiments, several observations were made from the study.

Firstly, $m i R-34 b / c$ methylation is tumor-specific as illustrated by the absence of methylation in normal peripheral blood and bone marrow cells, but complete methylation in 4 of the 7 CLL cell lines. Moreover, the expression of $m i R-34 b$ was also correlated inversely with the methylation status, with low miRNA expression in completely methylated cell lines and significantly higher expression in completely unmethylated cell lines. Furthermore, after the 5-AzadC treatment of MEC1 cells, the appearance of U-MSP signal, and hence demethylation of $m i R$ $34 b / c$ promoter, was associated with mature $m i R-34 b$ re-expression. Therefore, hypermethylation of $m i R-34 b /$ $c$ is prevalent in CLL cell lines, resulting in reversible miRNA silencing.

Secondly, $m i R-34 b / c$ is a tumor suppressor miRNA in CLL. This is demonstrated by the inhibition of cell proliferation and increase of cellular death upon over-expression of $m i R-34 b$ in MEC1 cells possessing complete methylation of $m i R-34 b / c$. Given the increasing evidence that TSGs are silenced by gene hypermethylation, promoter hypermethylation, together with inactivating gene mutation or deletion of the other allele may serve as one of the two hits of Knudson's hypothesis [2,33]. Moreover, $m i R-34 b / c$ is localized to $11 \mathrm{q} 23$ and hence, it is tempting to postulate that $m i R-34 b / c$ methylation might cooperate with del (11q) to inactivate both alleles of $m i R-34 b / c$, thereby fulfilling the Knudson's hypothesis [34]. However, in our samples, there was only one case of del (11q) to verify this hypothesis.

In contrast to $m i R-34 a$, which was rarely hypermethylated in CLL, $m i R-34 b / c$ was frequently methylated in CLL samples at diagnosis. However, there was no significant association between the methylation status of $m i R-34 b / c$ with clinical parameters, such as age, gender, diagnostic $\mathrm{Hb}$, lymphocyte or platelet count, Rai stage, or survival. However, it has been reported that the down regulation of $m i R-34$ family is involved CLL with an aggressive course [35]. In view of the small number of samples in our cohort, the impact of $m i R-34 b / c$ methylation on survival warrants a larger scale study. Nevertheless, infrequent miR-34a methylation was also contrasted with the frequent $m i R-34 a$ methylation in many epithelial cancers $[23,36]$.

Frequent methylation of DAPK1 was also observed in our patients, and 46.2\% (36/78) had methylation of either
$D A P K 1$ or $m i R-34 b / c$. Therefore, despite infrequent TP53 deletion or mutation in CLL at diagnosis, frequent $m i R-34 b / c$ or $D A P K 1$ methylation is implicated in the disruption of the TP53-centered tumor suppression network. This is particularly important as TP53 is also found to be haploinsufficient in carcinogenesis as inactivation of only one TP53 allele is sufficient to predispose to carcinogenesis [37].

Finally, an interesting observation was that methylation of $m i R-34 b / c$ (localized at chromosome 11q23) was associated with methylation of $m i R-203$ (localized at 14q32), similar to the association between miR-203 methylation with miR-34a, miR-124a, miR-196b and miR-129-2 methylation in non-Hodgkin's lymphoma [29,38]. $m i R-34 b / c$ and miR-203 have been shown independently to target $C R E B$ mRNAs $[39,40]$. As a transcription factor, CREB can upregulate the expression of multiple genes involved in the cell cycle progression (CCNA1, CCNB1 and CCND1) and survival (BCL2 and NFKB1) [39]. Therefore, concomitant methylation of both $m i R-203$ and $m i R-34 b / c$ might collaborate in the de-repression of CREB-related cell proliferation and survival, contributing to carcinogenesis.

\section{Conclusion}

In conclusion, $m i R-34 b / c$ methylation is a tumor suppressor miRNA frequently methylated in CLL. $m i R-34 b /$ $c$ methylation is associated with reversible miRNA silencing. Despite the infrequent occurrence of inactivating TP53 mutation in CLL at diagnosis, $m i R-34 b / c$ methylation, together with $D A P K 1$ methylation, is implicated in the perturbation of the TP53-centered tumor suppressor network. Finally, the implication of association of miR$34 \mathrm{~b} / \mathrm{c}$ methylation with that of $m i R-203$ warrants further analysis.

\section{Additional file}

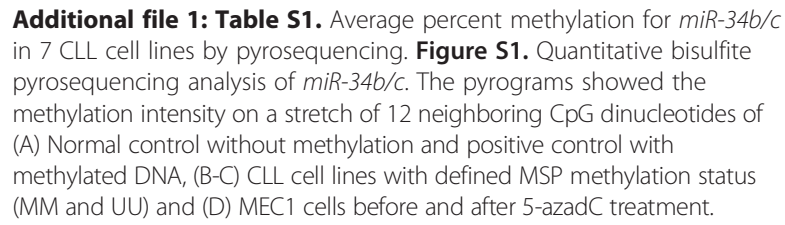

Additional file 1: Table S1. Average percent methylation for miR-34b/c in 7 CLL cell lines by pyrosequencing. Figure S1. Quantitative bisulfite pyrosequencing analysis of miR-34b/c. The pyrograms showed the methylation intensity on a stretch of 12 neighboring $\mathrm{CpG}$ dinucleotides of (A) Normal control without methylation and positive control with methylated DNA, (B-C) CLL cell lines with defined MSP methylation status (MM and UU) and (D) MEC1 cells before and after 5-azadC treatment.

\section{Abbreviations \\ CLL: Chronic lymphocytic leukemia; TSGs: Tumor suppressor genes; miRNAs: microRNAs; MSP: Methylation-specific polymerase chain reaction; 5-AzadC: 5-Aza-2'-deoxycytidine.}

\section{Competing interests}

The authors confirm that there are no conflicts of interest.

\section{Authors' contributions}

Conceived and designed the experiments: CSC and YLK. Acquisition of data: CSC, KFW, CSBK and ET. Analyzed the data: CSC, LQW and DYJ. Performed the experiments: LQW. Writing, review, and/or revision of the manuscript: 
LQW, CSC, YLK, KFW, CSBK, DYJ, ET and AR. All authors read and approved the final manuscript.

\section{Acknowledgements}

We would like to thank Dr. John Byrd, Department of Medicine, Ohio State University, USA for the CLL cell lines (MEC2, WAC3CD5+ and 183-E95), and his critical review of the manuscript.

\section{Author details}

${ }^{1}$ Department of Medicine, Queen Mary Hospital, The University of Hong Kong, Hong Kong, China. ${ }^{2}$ Department of Pathology, Queen Elizabeth Hospital, Hong Kong, China. ${ }^{3}$ Department of Medicine, Pamela Youde Nethersole Hospital, Hong Kong, China. ${ }^{4}$ Department of Biochemistry, The University of Hong Kong, Hong Kong, China. ${ }^{5}$ Department of Clinical \& Experimental Medicine, Linköping University, Linköping, Sweden.

Received: 5 November 2013 Accepted: 19 February 2014 Published: 22 February 2014

\section{References}

1. Esteller M: Epigenetics in cancer. N Engl J Med 2008, 358:1148-1159.

2. Chim CS, Liang R, Kwong YL: Hypermethylation of gene promoters in hematological neoplasia. Hematol Oncol 2002, 20:167-176.

3. Jones PA, Baylin SB: The epigenomics of cancer. Cell 2007, 128:683-692

4. Rush LJ, Plass C: Alterations of DNA methylation in hematologic malignancies. Cancer Lett 2002, 185:1-12.

5. Gonzalez-Zulueta M, Bender CM, Yang AS, Nguyen TD, Beart RW, Van Tornout JM, Jones PA: Methylation of the $5^{\prime} \mathrm{CpG}$ island of the p16/ CDKN2 tumor suppressor gene in normal and transformed human tissues correlates with gene silencing. Cancer Res 1995, 55:4531-4535.

6. Chim CS, Fung TK, Cheung WC, Liang R, Kwong YL: SOCS1 and SHP1 hypermethylation in multiple myeloma: implications for epigenetic activation of the Jak/STAT pathway. Blood 2004, 103:4630-4635.

7. Chim CS, Liang R, Fung TK, Choi CL, Kwong YL: Epigenetic dysregulation of the death-associated protein kinase/p14/HDM2/p53/Apaf-1 apoptosis pathway in multiple myeloma. J Clin Pathol 2007, 60:664-669.

8. Xiang T, Li L, Yin X, Zhong L, Peng W, Qiu Z, Ren G, Tao Q: Epigenetic silencing of the WNT antagonist Dickkopf 3 disrupts normal Wnt/ $\beta$-catenin signalling and apoptosis regulation in breast cancer cells. J Cell Mol Med 2013, 17:1236-1246.

9. Liu TH, Raval A, Chen SS, Matkovic JJ, Byrd JC, Plass C: CpG island methylation and expression of the secreted frizzled-related protein gene family in chronic lymphocytic leukemia. Cancer Res 2006, 66:653-658

10. Raval A, Tanner SM, Byrd JC, Angerman EB, Perko JD, Chen S-S, Hackanson B, Grever MR, Lucas DM, Matkovic JJ, Lin TS, Kipps TJ, Murray F, Weisenburger D, Sanger W, Lynch J, Watson P, Jansen M, Yoshinaga Y, Rosenquist R, de Jong PJ, Coggill P, Beck S, Lynch H, de la Chapelle A, Plass C: Downregulation of death-associated protein kinase 1 (DAPK1) in chronic lymphocytic leukemia. Cell 2007, 129:879-890.

11. Chim CS, Pang R, Liang R: Epigenetic dysregulation of the Wnt signalling pathway in chronic lymphocytic leukaemia. J Clin Pathol 2008, 61:1214-1219.

12. Calin GA, Croce CM: MicroRNA signatures in human cancers. Nat Rev Cancer 2006, 6:857-866.

13. Bartel DP: MicroRNAs: target recognition and regulatory functions. Cell 2009, 136:215-233.

14. Sana J, Faltejskova P, Svoboda M, Slaby O: Novel classes of non-coding RNAs and cancer. J Trans/ Med 2012, 10:103.

15. Weinberg RA: Tumor suppressor genes. Science 1991, 254:1138-1146.

16. Harris CC, Hollstein M: Clinical implications of the p53 tumor-suppressor gene. N Engl J Med 1993, 329:1318-1327.

17. Zenz T, Eichhorst B, Busch R, Denzel T, Häbe S, Winkler D, Bühler A, Edelmann J, Bergmann M, Hopfinger G, Hensel M, Hallek M, Döhner H, Stilgenbauer S: TP53 Mutation and survival in chronic lymphocytic leukemia. J Clin Oncol 2010, 28:4473-4479.

18. Rossi D, Cerri M, Deambrogi C, Sozzi E, Cresta S, Rasi S, De Paoli L, Spina V, Gattei V, Capello D, Forconi F, Lauria F, Gaidano G: The prognostic value of TP53 mutations in chronic lymphocytic leukemia is independent of Del17p13: implications for overall survival and chemorefractoriness. Clin Cancer Res 2009, 15:995-1004.

19. Kohler M, Kerns B, Humphrey P, Marks J, Bast R Jr, Berchuck A: Mutation and overexpression of p53 in early-stage epithelial ovarian cancer. Obstet Gynecol 1993, 81:643.
20. Chim CS, Fung TK, Wong K, Lau J, Liang R: Frequent DAP kinase but not p14 or Apaf-1 hypermethylation in B-cell chronic lymphocytic leukemia. J Hum Genet 2006, 51:832-838.

21. Hallek M, Cheson BD, Catovsky D, Caligaris-Cappio F, Dighiero G, Döhner H, Hillmen P, Keating MJ, Montserrat E, Rai KR, Kipps TJ: Guidelines for the diagnosis and treatment of chronic lymphocytic leukemia: a report from the international workshop on chronic lymphocytic leukemia updating the national cancer institute-working group 1996 guidelines. Blood 2008, 111:5446-5456.

22. Jaffe ES: Pathology and Genetics of Tumours of Haematopoietic and Lymphoid Tissues. Lyon: LARC Press; 2001

23. Chim CS, Wong KY, Qi Y, Loong F, Lam WL, Wong LG, Jin D, Costello JF, Liang R: Epigenetic inactivation of the miR-34a in hematological malignancies. Carcinogenesis 2010, 31:745-750.

24. Stacchini A, Aragno M, Vallario A, Alfarano A, Circosta P, Gottardi D, Faldella A, Rege-Cambrin G, Thunberg U, Nilsson K: MEC1 and MEC2: two new cell lines derived from B-chronic lymphocytic leukaemia in prolymphocytoid transformation. Leuk Res 1999, 23:127-136.

25. Wendel-Hansen V, Sällström J, De Campos-Lima P, Kjellström G, Sandlund A, Siegbahn A, Carlsson M, Nilsson K, Rosen A: Epstein-barr virus (EBV) can immortalize B-cll cells activated by cytokines. Leukemia 1994, 8:476.

26. Rosén A, Bergh AC, Gogok P, Evaldsson C, Myhrinder AL, Hellqvist E, Rasul A Björkholm M, Jansson M, Mansouri L: Lymphoblastoid cell line with B1 cell characteristics established from a chronic lymphocytic leukemia clone by in vitro EBV infection. Oncol Immunol 2012, 1:18-27.

27. Lujambio A, Calin GA, Villanueva A, Ropero S, Sánchez-Céspedes M, Blanco D, Montuenga LM, Rossi S, Nicoloso MS, Faller WJ: A microRNA DNA methylation signature for human cancer metastasis. Proc Natl Acad Sci USA 2008, 105:13556-13561.

28. Wong KY, Yim RLH, So CC, Jin DY, Liang R, Chim CS: Epigenetic inactivation of the MIR34B/C in multiple myeloma. Blood 2011, 118:5901-5904.

29. Chim CS, Wong KY, Leung CY, Chung LP, Hui PK, Chan SY, Yu L: Epigenetic inactivation of the hsa-miR-203 in haematological malignancies. J Cell Mol Med 2011, 15:2760-2767.

30. Livak KJ, Schmittgen TD: Analysis of relative gene expression data using realtime quantitative PCR and the $2^{{ }^{\Delta}} \mathrm{CT}$ method. Methods 2001, 25:402-408.

31. Narayan G, Arias-Pulido H, Koul S, Vargas H, Zhang F, Villella J, Schneider A, Terry M, Mansukhani M, Murty V: Frequent promoter methylation of CDH1, DAPK, RARB, and HIC1 genes in carcinoma of cervix uteri: its relationship to clinical outcome. Mol Cancer 2003, 2:24.

32. Wong KY, So CC, Loong F, Chung LP, Lam WW, Liang R, Li GK, Jin DY, Chim CS: Epigenetic inactivation of the miR-124-1 in haematological malignancies. PLOS One 2011, 6:e19027.

33. Knudson AG: Karnofsky memorial lecture. Hereditary cancer: theme and variations. J Clin Oncol 1997, 15:3280-3287.

34. Haferlach C, Dicker F, Schnittger S, Kern W, Haferlach T: Comprehensive genetic characterization of CLL: a study on 506 cases analysed with chromosome banding analysis, interphase FISH, IgVH status and immunophenotyping. Leukemia 2007, 21:2442-2451.

35. Cardinaud B, Moreilhon C, Marcet B, Robbe-Sermesant K, LeBrigand K, Mari B, Eclache V, Cymbalista F, Raynaud S, Barbry P: miR-34b/miR-34c: a regulator of TCL1 expression in 11q- chronic lymphocytic leukaemia. Leukemia 2009, 23:2174-2177.

36. Lodygin D, Tarasov V, Epanchintsev A, Berking C, Knyazeva T, Korner H, Knyazev $\mathrm{P}$, Diebold J, Hermeking H: Inactivation of miR-34a by aberrant CpG methylation in multiple types of cancer. Cell Cycle 2008, 7:2591-2600.

37. Berger $\mathrm{AH}$, Knudson AG, Pandolfi PP: A continuum model for tumour suppression. Nature 2011, 476:163-169.

38. Wong KY, Yim RLH, Kwong YL, Leung CY, Hui PK, Cheung F, Liang R, Jin DY, Chim CS: Epigenetic inactivation of the MIR129-2 in hematological malignancies. J Hematol Oncol 2013, 6:16.

39. Pigazzi M, Manara E, Baron E, Basso G: miR-34b targets cyclic AMP-responsive element binding protein in acute myeloid leukemia. Cancer Res 2009, 69:2471-2478.

40. Wong KY, Liang R, So CC, Jin DY, Costello JF, Chim CS: Epigenetic silencing of MIR203 in multiple myeloma. Br J Haematol 2011, 154:569-578.

doi:10.1186/1479-5876-12-52

Cite this article as: Wang et al:: Epigenetic inactivation of $\mathrm{mir}-34 \mathrm{~b} / \mathrm{c}$ in addition to mir-34a and DAPK1 in chronic lymphocytic leukemia. Journal of Translational Medicine 2014 12:52. 